\title{
Effects of Computer-Assisted Career \\ Decision Making on Vocational Identity and \\ Career Exploratory Behaviors
}

Wei-Cheng Mau

The use of computer technology for career counseling has become a standardized practice among counseling professionals since its first introduction to the field. The possible utilities and limitations of computer-assisted career guidance systems (CACG) have been widely discussed (e.g., Harris-Bolsbey, 1984; Gati, 1995; Katz, 1993; Sampson, 1983). The cost analyses and the evaluation of CACG have also been documented (e.g., Sampson, Reardon, Humphreys, Peterson, Evans, \& Domkowski, 1990). However, the effectiveness of CACG has not been systematically investigated as has other traditional career interventions. CACG systems vary greatly in the amount of validity and reliability data available. While the vast majority of service delivery sites (i.e., educational institutions, employment, or training agencies) are making use of CACG systems, many practitioners often overlook the validity and reliability factors for system selection (Sampson, 1994). The majority of CACG studies were conducted during the $70 \mathrm{~s}$ and $80 \mathrm{~s}$ [see a review by Cairo (1983)]. Due to the vast and rapid change of the technology and the delivery system, continued research and evaluation of the effectiveness of CACG is needed. The purpose of this study is to compare and evaluate relative effectiveness of differ-ent approaches to computer-based career interventions.

CACG systems provide many attractive features for experimental research on career decision-making, largely due to its standardization of treatment procedure and replicability of results (Jepsen, 1990). CACG systems also provide a linkage between theory and practice 
(Walsh \& Savickas, 1996). Despite the potential of CACG, these systems have not received enough attention in the field of counseling psychology (Gati, 1996).

Although there are more than a dozen popular systems, studies have been unevenly focused on a few programs such as DISCOVER and SIGI. Most of the CACG studies concentrated on the likability of these systems and its short-term effect (Cairo, 1983). Very few studies focused on the effect of the systems on individuals' vocational identity or career development over an extended period of time. Moreover, CACG programs are complex systems, where effects on users are likely to be the product of complex interaction. Therefore, isolating components of a large system and investigating the interactions with other system components is important (Jepsen, 1990).

Most of the CACG systems are designed to assist an individual in learning about themselves (i.e., career assessment approach), or learning about the world of work, (i.e., career exploration approach). Very few systems are designed to teach individuals about how to process career information (i.e., decision making approach). If the ultimate goal of career intervention is to help individuals become independent and responsible career problem-solvers and decision-makers, then the teaching of information processing skills and decisionmaking strategies must be developed (Sampson, Peterson, \& Reardon, 1989).

Career decision-making is a complex process, by which individuals organize information about themselves and the world of work, deliberate among alternatives about actions, and make a public commitment to action (Jepsen, 1984). It has been strongly suggested that individuals usually lack the cognitive capacity to process information about self and occupation (Kahneman, 1991, Tversky, 1975). Janis and Mann (1977) provide considerable empirical evidence that humans are swayed by emotional and motivational forces that lead to defective decision making. Given the complexity of the decisionmaking process, and the limitations of human cognition, teaching individuals to understand the decision process and appropriate career decision-making strategies is crucial.

Janis and Mann (1977) suggest that it is possible to improve the quality of decision making through decision counseling procedures. Studies (Egner \& Jackson, 1978; Jepsen, Dustin, \& Miars, 1982; Krumboltz, Scherba, Hamel, \& Mitchell, 1982; Rubinton, 1980) have shown the effectiveness of direct teaching about decision-making strategies. Very few studies have investigated the effectiveness of 
teaching career-decision making via computers. Johnson (1985) used microcomputers to teach steps in the decision-making process and help students learn how to use personal interest, values, and abilities to evaluate career options. He found that the students in the computer-assisted group perceived the career exploration to be more enjoyable and helpful than did students in the counselorassisted group.

Decision-making models traditionally have been classified as either prescriptive or descriptive in nature (Janis \& Mann, 1977; Jepsen, 1975). Prescriptive models concern with making a "right" decision whereas the descriptive models specify how people actually make decisions. Perhaps, the Subjective Expected Utility (Katz, 1966) and the Elimination by Aspects (Gati, 1986) are the two models most representative of the prescriptive and the descriptive models. The Subjective Expected Utility (SEU) decision model emphasizes making optimal decisions, i.e., decisions which meet a set of axioms that a completely "rational" decision maker would consider desirable. For example, the decision-maker is taught to specify desired outcomes, estimate the probability of securing the desired outcomes, and evaluate each option based on the expected utilities associated with each option. The Elimination by Aspects (EBA), on the other hand, focuses on choices that are "good enough", i.e., decisions that satisfy a mini-mal set of criteria rather than an optimal set. This model requires the decision-maker to delimit relevant aspects, and use the delimited aspects to eliminate options that do not meet the specified requirements, one at a time, until only a few options remain. The compo-nents of the SEU and EBA models were described in the method section.

Efficacy of the SEU and EBA decision models have been investigated. For example, using microcomputers as instructional media to teach college students about choosing an academic major, Mau and Jepsen (1992) compared the effects of the two theory-based decision strategies, with a wait-listed control group. Their findings suggest a differential impacts of the strategies on choice anxiety, choice certainty, and complexity of reasons for choosing a college major. Lichtenberg, Shaffer, and Arachtingi (1993) have also compared SEU and EBA decision models using a work sheet approach. Their study sug-gested that the SEU yielded a significantly higher payoff. Based on these findings and suggestions from Gati (1986), it may be hypothe-sized that computer programs that integrate two strategies may have a greater impact on an individual's career decision-making tasks.

The purpose of this study was to investigate effects of a computer 
program combining Subjective Expected Utilities and Elimination by Aspects decision strategies, on vocational identity, career exploratory behaviors, and satisfaction with CACG programs. The relative effectiveness of different CACG approaches was also examined. Not only did this study use multiple outcome measures, but also a 6-month follow-up was used to establish the long-term effects of the CACG programs. Specifically, the following questions were addressed in this study:

A. Does teaching career decision-making strategies (CDM) result in a greater vocational identity and career exploratory behaviors?

B. How does the COM approach compare with the career interest assessment approach (SDS), the information approach (CHOICES), and a combination approach (SOS + CDM)? Which approach has greater long-term effects?

C. How are the CACG programs received by students?

Vocational identity is defined as the possession of a clear and stable

picture of one's goals, interests, and talents (Holland, Johnston, \& Asama, 1993). Vocational identity has been found to associate with vocational commitment (Grotevant \& Thorbecke, 1982), vocational maturity (Crites, 1978), positive career belief (Krumboltz, 1991), desirable problem solving attitude (Heppner \& Krieshok, 1983), and rational decision-making style (Leong \& Morris, 1989). The most popular use of this scale has been its use as a pre/post criterion for evaluating career intervention (Holland et al., 1993).

Career exploratory behavior has been defined as those activities in which individuals seek to assess themselves and acquire information from the environment to assist with decision-making (Jordaan, 1963). Career exploratory behaviors have been shown to be predictive of vocational commitment (Blustein, 1989), vocational maturity (Yongue, Todd, \& Burton, 1981), congruent occupational preference (Grotevant, Cooper, \& Kramer, 1986), and confidence in one's vocational choice (Jepsen, 1975).

Methods

\section{Participants}

The participants consisted of $108(M=26, F=82)$ undergraduate students enrolled in human growth and development classes at a midwestern state university. Students (approximately 150) enrolled 
in these classes were primarily juniors and seniors. Of the 150 students, 121 agreed to participate. Of the 121 volunteers, 108 completed the study. Students who completed the study were given extra course credits. The median age was $22.5(S D=6.8)$, ranging from 18 to 48 . The majority of participants (over $90 \%$ ) were Caucasians.

\section{CACG Programs}

Three types of CACGs were examined. Program descriptions are briefly stated as followings:

Career Decision-Making (CDM). CDM is a computer-assisted instruction program that teaches theory-based career decision-making strategies. The computer instruction program was created by the author based on the decision-making models Elimination by Aspects and the Subjective Expected Utility as described by Gati (1986) and Katz (1966). The Elimination strategy contains five sections: (a) generating a list of choice possibilities, (b) identifying a list of aspects, (c) clarifying aspects, (d) eliminating possibilities by aspects, and (e) ordering the surviving alternatives. The Maximizing strategy contains 4 sections: (a) identifying and comparing values, (b) estimating expectancies, (c) computing expected values, and (d) evaluating the alternatives. For each section, instructions include learning objectives, activity instructions, and simulation exercises, i.e., Career Grid (Mau, 1997) and Vocational Card Sort (Dolliver, 1967). A list of occupations and information resources (e.g., career placement services) is included in the computer program along with suggestions on how to search for additional, offline information.

Self-Directed Search-Computer Version (SDS-CV; PAR, 1987). As both a vocational assessment and an intervention design, the paperpencil version of SDS has been shown to increase self-understanding, and the number of vocational options considered (Holland, Power, \& Fritzsche, 1994). The creation of a computer version is intended to "extend the assessment and treatment where possible in ways compatible with Holland's most recent theory" (Reardon, 1987, p. 63). The SDS-CV items are identical with those of the paper-and pencil version. Using summary scale scores, Reardon and Loughead (1988) compared SDS and SDS-CV indicating a significant correlation. The SDS-CV provides an interpretive report including an overview of the six Holland types. The report also includes suggestions on how to use 
the SDS results in career and educational planning, and a list of reference materials. SDS-CV has been used to assist "those clients indicating a lack of adequate self-knowledge or schema with which relates to personal characteristics to occupations" (Reardon, Lenz, \& Strausberger, 1996, p. 213).

Heuristic Occupational Information and Career Exploration System (CHOICES; Careerware, 1996). CHOICES has a strong emphasis on information access and retrieval. There are five modules in the CHOICES program: (a) Guided Access, (b) Tutorial, (c) Planner, (d) Assessment, and (e) Quick Access. In this study, only the Guided Access module was used to represent the information approach of the CACG interventions. The Guided Access module contains a search function that allows individuals to explore occupations based on their selected criteria such as interest, aptitude, temperaments, etc. This module also allows individuals to compare two or three occupations, and search related occupations. Studies have indicated that CHOICES was well received (e.g., Reardon, Bonnell, \& Huddleston, 1982), and increased career decision making commitment of college students (e.g., Pinder \& Fitzgerald, 1984).

\section{Instrument}

Vocational identity. My Vocational Situation (Holland, Daiger, \& Power, 1980) measured vocational identity, the need for information, and perceived barriers to career decision-making. The vocational identity scale, consisted of $\mathbf{1 8}$ items, is defined as " the possession of a clear and stable picture of one's goal, interests, personality, and talents" (Holland et al., 1980, p. 1). A high score suggests a clear and stable vocational identity. The score reliability (KR 20) is .89 for 291 college males, and .88 for college females. MVS has been gaining empirical support as a valid diagnostic tool (Holland et al., 1993; Lucas, Gysbers, Buescher, \& Heppner, 1988).

Career exploratory behaviors. A checklist, including 20 possible sources of information, was developed by the author. Participants were asked to indicate how often they had sought each information since they received CACG. Both the number of sources and the total frequencies of information sought were assessed. A high score suggests a high level exploratory behavior. 
Satisfaction ratings. Students' satisfaction with the program was measured based on a questionnaire composed of 10 self-descriptive statements, for example, "Using this program helped me to make the educational/vocational decisions." Items were derived from several studies, including Ryan and Drummond (1981), and Mau and Jepsen (1992). Students rated each of the 10 statements using a 5-point Likert scale (from 1, strongly disagree, to 5, strongly agree). For the first eight statements, a high rating ( 3 and above) indicated a positive reaction to the program utilized; for the last two statements, a high rating indicated a negative reaction toward the program. Ratings for the last two items were reversed when the total satisfaction ratings were computed. The alpha coefficient estimated for this sample was.76.

\section{Procedure}

Students who participated in this study were randomly assigned to one of six groups: (1) CDM, (2) SDS, (3) CHOICES, (4) SDS + CDM, (5) wait-listed control, and (6) hold-out group. A total of 25 two-hour sessions were scheduled over a two-week period. Due to limited availability of computers and the software programs, seven participants were assigned to a different group because none of the originally assigned group sessions fit their schedule. Consequently, each session varied with a number of students participating. In each session, a graduate research assistant was available for introducing the computer system and answering questions.

Students who participated in any of the first four CACG groups completed the My Vocational Situation questionnaire (MVS) one week before they received the treatment, and were administered the MVS and a computer program evaluation questionnaire immediately after the treatment. A Career Exploratory Behavior checklist and MVS were administered to the treatment groups six months after they received the treatment. Students in the wait-listed control group completed MVS twice in the same one-week period before they received the treatment. Students in the hold-out group were administered MVS in the pretest and the MVS and the career exploratory behav-iors checklist during the follow-up period. Students in the hold-out group received no treatment during the research study period. See Table 1 for a description of the experimental design. 
Table 1

Design of Study

\begin{tabular}{|c|c|c|c|c|c|}
\hline Group & $n$ & Pretest & Treatment & Posttest & Follow-up \\
\hline CDM & 22 & $\mathrm{O}_{1}$ & $\mathbf{x}$ & $\mathrm{O}_{2}$ & $\mathrm{O}_{3}$ \\
\hline SDS & 14 & $\mathrm{O}_{1}$ & $\mathbf{x}$ & $\mathrm{O}_{2}$ & $\mathrm{O}_{3}$ \\
\hline CHOICES & 20 & $\mathrm{O}_{1}$ & $\mathbf{x}$ & $\mathrm{O}_{2}$ & $\mathrm{O}_{3}$ \\
\hline $\mathrm{SDS}+\mathrm{CDM}$ & 13 & $\mathrm{O}_{1}$ & $\mathbf{x}$ & $\mathrm{O}_{2}$ & $\mathrm{O}_{3}$ \\
\hline Wait-list & 18 & $\mathrm{O}_{1}$ & $\mathrm{O}_{2}$ & & \\
\hline Hold-out & 21 & $\mathrm{O}_{1}$ & & & $\mathrm{O}_{3}$ \\
\hline
\end{tabular}

Note. $\mathrm{O}_{1}=$ Pretest, $\mathrm{O}_{2}=$ Posttest, $\mathrm{O}_{3}=$ Follow-up, $\mathrm{x}=$ Treatment.

\section{Results}

\section{Short Term Effect on Identity}

Table 2 provides means and standard deviations of vocational identity scores by groups and gender. We used a two-way ANOVA (5 groups $x 2$ sexes) to examine the short-term gain among the groups. Pretest and posttest differences in vocational identity among CACG and wait-listed control groups were examined. Results of ANOVA indicate a significant short-term gain in vocational identity for groups,

Table 2

Means and Standard Deviations of Vocational Identity by Groups and Gender

\begin{tabular}{lccc}
\hline & $\begin{array}{c}\text { Pretest } \\
M(S D)\end{array}$ & $\begin{array}{c}\text { Posttest } \\
M(S D)\end{array}$ & $\begin{array}{c}\text { Follow-up } \\
M(S D)\end{array}$ \\
\hline CDM $(n=22)$ & $13.1(2.8)$ & $15.5(2.4)$ & $16.4(1.5)$ \\
SDS $n=14)$ & $13.6(3.6)$ & $14.1(4.0)$ & $15.0(3.2)$ \\
CHOICES $(n=20)$ & $11.0(4.4)$ & $12.3(4.6)$ & $14.8(3.2)$ \\
SDS + CDM $(n=13)$ & $12.9(3.8)$ & $14.9(3.5)$ & $15.0(3.1)$ \\
Wait-Listed Control $(n=18)$ & $13.3(3.7)$ & $13.6(3.9)$ & - \\
Hold-out Group $(n=21)$ & $14.7(2.6)$ & - & $15.4(2.1)$ \\
Males $(n=26)$ & $13.7(3.8)$ & $14.1(4.0)$ & $15.3(3.1)$ \\
Females $(n=82)$ & $12.8(3.7)$ & $14.8(3.5)$ & $15.6(2.7)$ \\
\hline
\end{tabular}


$F(4,87)=2.69, p<.037$. There were no significant gender differences or group by gender interaction. Post hoc analysis indicated that students who participated in the CDM group $(M=2.32)$ had a significant short-term gain on vocational identity than those students who were in the wait-listed control group $(M=0.28)$.

\section{Long Term Effect on Identity}

We used a two-way ANOVA (5 groups $\times 2$ sexes) to examine the long term gain among the groups. Pretest and follow-up test differences in vocational identity among CACG and hold-out groups were examined. Results of ANOVA also indicated a significant long-term gain in vocational identity for groups, $F(4,69)=3.29, p<.017$. Post hoc analysis showed that students in the CDM $(M=3.30)$, or CHOICES group ( $M=3.71$ ) had a significant long-term gain when compared to the hold-out group $(M=0.70)$.

\section{Differences in Exploratory Behaviors}

Table 3 provides means and standard deviations of career exploratory behaviors by group and gender. Results of ANOVA indicate a significant group by sex interaction for source of information explored, $F(4,69)=3.03, p<.024$, and in the total frequencies of information sought, $F(4,87)=3.49, p<.013$. Post hoc analyses showed that male participants in the CDM group $(M=11.2)$ sought significantly more sources of information than male participants in the

Table 3

Means and Standard Deviations of Exploratory Behaviors by Groups and Gender

\begin{tabular}{lccccc}
\hline & \multicolumn{2}{c}{$\begin{array}{c}\text { Number ofSources } \\
\text { Explored }\end{array}$} & & \multicolumn{2}{c}{$\begin{array}{c}\text { Frequency of } \\
\text { Exploration }\end{array}$} \\
\cline { 2 - 3 } \cline { 5 - 6 } $\begin{array}{l}\text { Treatment } \\
\text { Groups }\end{array}$ & Males & Females & & Males & Females \\
\hline CDM & $11.2(3.1)$ & $6.2(2.6)$ & & $59.2(34.4)$ & $19.6(18.5)$ \\
SDS & $6.0(2.8)$ & $6.0(3.3)$ & & $59.5(55.9)$ & $19.4(14.4)$ \\
CHOICES & $5.5(4.5)$ & $7.6(3.1)$ & & $11.5(10.8)$ & $27.7(30.5)$ \\
SDS+ CDM & $9.3(3.1)$ & $8.1(2.7)$ & & $38.3(24.7)$ & $25.9(16.5)$ \\
Hold-Out Group & $5.0(2.8)$ & $6.1(2.4)$ & & $19.8(21.2)$ & $17.4(10.6)$ \\
\hline
\end{tabular}


hold-out group ( $M=5.0)$. For the CDM group, male participants significantly sought more sources of information, $F(1,16)=11.72$, $p<.004$, and more frequent in the information sought, $F(1,16)=$ $9.81, p<.007$, than female participants.

\section{Satisfaction with Programs}

Perceived satisfaction with CACG programs (i.e., CDM, SDS-CV, and CHOICES) was examined using one-way ANOVA. Results showed a significant difference in satisfaction ratings among the different CACG programs, $F(2,55)=4.42, p<.017$. On the average, students who used the SD-CV program $(M=43.1, S D=5.1)$ reported greater satisfaction than those who used the $\operatorname{CDM}(M=36.0, S D=7.9)$ or CHOICES $(M=36.9, S D=8.4)$ program. No significant gender differences were found.

\section{Discussion}

This study investigated the effectiveness of a theory-based CACG program, integrating Sequential Elimination and Expected Utility strategies. Results, yielding support to Gati (1986) and Janis and Mann's (1977) contentions, suggested that it is not only possible to integrate decision-making strategies, but also indicated that the integrated approach is effective in increasing students' vocational identity. Teaching career decision-making strategies using microcomputers, not only resulted in a short-term gains in students' vocational identity, but the impact also seems to be long lasting. The information approach (CHOICES) also had a significant long-term impact on students' vocational identity, but fell short of a significant short-term effect. Although SOS-CV did not significantly raise students' vocational identity scores, students appeared to favor the use of SDS-CV over CDM and CHOICES.

Unexpectedly, the combined approach (SDS + CDM) did not significantly increase students' vocational identity. Several possible explanations are offered: one, the arrangement to do both computer programs was difficult to make, consequently, fewer students showed up for the experiment. Two, the considerably smaller sample size for the combined approach may have resulted in lacking statistical power for a significant effect. It is also possible that ceiling effect may be a factor for this non-significant finding. University career counseling cli- 
ents typically have an average vocational identity score of 8 (R.C., Reardon; personal communication, January 12, 1997). The sample from this study consisted of primarily junior and senior university students who were likely to have their career goals well thought out and formulated.

Consistent with other studies (Johnson, 1985; Miller, Karriker, \& Springer, 1986), the present study did not show gender effects of these treatment programs on vocational identity. However, gender and treatment interaction was found for the measure of vocational exploratory behavior. Male students in the CDM group sought significantly more sources of information than male participants in the hold-out group. The fact that the CDM program does not contain occupational information, and its provision of strategy to obtain offline information, seemed to have motivated male students more than female students to seek information from diverse sources. However, due to a relatively small male sample size in each group, one should interpret the findings with reservation and make tentative conclusions.

Vocational identity and vocational exploratory behavior are generally considered two important predictors for a variety of career behaviors and major career intervention goals. Given the complexity of the decision-making process, and the limitations of human information processing, computer-assisted career intervention programs can be used to break down the information into "bits" and "pieces," therefore, reducing the "information overload." Teaching career decision-making can consume a great deal of a counselor's time. The use of CACG for teaching career decision-making not only enhances counselors productivity, but also becomes a logical solution for often criticized com-pensatory decision models (Glass \& Holyoak, 1986; Mann, 1989; Tversky, 1975). By tailoring the computer program to each individual's unique situation, we are able to effect significant change on in-dices of vocational identity and exploratory behaviors.

Although students were more satisfied with the SDS program, both CDM and CHOICES programs were rated positively. More than $50 \%$ of students from either program indicated that they would suggest to their friends to use the program. An interesting finding of this study is that user satisfaction does not necessarily correlate with the objective indexes of benefits. This is particularly important to be noted, as many studies seems to only collect satisfaction data and then imply that if the students liked it, it must be beneficial. Counselors should avoid making decisions based on a single factor. Cost-effect analysis (e.g., Sampson et al., 1990) would provide useful information to the 
practitioners. The result of this study is by no mean to be used to advocate that computers replace counselors. There are an ample number of career problems that are not ready to be addressed by computerized programs.

Generations from this study are limited because of the limited selection of sample and outcome measures. The participants in this study were quite advanced in their undergraduate program and were likely to have their career goals well thought out. Nevertheless, given this advanced career status and such a brief intervention session, impacts of the CACGs were still noticeable. It is therefore reasonable to hypothesize that the CACGs may have a greater impact on students who are less advanced in their career development process. To verify this hypothesis, the methods and procedures can be replicated on more diverse student populations. Furthermore, future studies can also use outcome measures that directly assess decision-making ability and efficacy. In particular, it may be interesting to investigate how different CACGs provide different help for the students.

References

Blustein, D.L. (1989). The role of career exploration in the career decision making of college students. Journal of College Student Development, 30, 111-117.

Cairo, P.C. (1983). Evaluating the effects of computer-assisted counseling systems: A selective review. The Counseling Psychologist, 11 (4), 55-59.

Careerware (1996). CHOICES [computer program]. Ottawa, Ontario: Author.

Crites, J.O. (1978). Administration and use manual for the Career Maturity Inventory. Odessa, FL: Psychological Assessment Resources.

Dolliver, R.H. (1967). An adaptation of Tyler Vocational Card Sort. Personnel and Guidance Journal, 45, 916-920.

Egner, J.R., \& Jackson, D.J. (1978). Effectiveness of a counseling intervention program for teaching career decision-making skills. Journal of Counseling Psychology, 25, 4552.

Gati, I. (1986). Making career decisions-A sequential elimination approach. Journal of Counseling Psychology, 33, 408-417.

Gati, I. (1995). Computer-assisted career counseling: Dilemmas, problems and possible solutions. Journal of Counseling and Development, 73, 51-56.

Gati, I. (1996). Computer-assisted career counseling: Challenges and prospects. In M.L. Savickas, \& W.B. Walsh (Eds.), Handbook of career counseling theory and practice.

Palo Alto, CA: Davies-Black Publishing.

Glass, A.L., \& Holyoak, K.J. (1986). Cognition (2nd ed.). New York: Random House.

Grotevant, H.D., \& Thorbecke, W.L. (1982). Sex differences in styles of occupational identity formation in late adolescents. Development Psychology, 18, 396-405.

Grotevant, H.D., Cooper, C.R., \& Kramer, K. (1986). Exploration as a predictor of congruence in adolescents' career choices, Journal of Vocational Behavior, 29, 201-215. Harris-Bowlsbey, J. (1984). The computer and career development. Journal of Career Development, 63, 145-148.

Heppner, P.P., \& Krieshok, T.S. (1983). An applied investigation of problem-solving ap- 
praisal, vocational identity, and career service requests, utilization, and subsequent evaluation. Vocational Guidance Quarterly, 31, 240-249.

Holland, J.L., Daiger, D.C., \& Power, P.G. (1980). My Vocational Situation. Palo Alto,CA: Consulting Psychologists Press.

Holland, J., Power, A.B., \& Fritzsche, B.A. (1994). The Self-Directed Search: Professional User's Guide. Odessa, FL: Psychological Assessment Resource.

Holland, J.L., Johnston, J.A., \& Asama, N.F. (1993). The Vocational Identity Scale: A diagnostic and treatment tool. Journal of Career Assessment, 1, 1-12.

Janis, I.L., \& Mann, L. (1977). Decision-making: A psychological analysis of conflict, choice, and commitment. New York: Free Press.

Jepsen, D.A.(1975). Occupational decision development over the high school years. Journal of Vocational Behauior, 7, 225-237.

Jepsen, D.A.(1984). The developmental perspective on vocational behavior: A review of theory and research. In S.D. Brown, \& R.W. Lent (Eds.), Handbook of Counseling

Psychology, New York: Wiley.

Jepsen, D.A. (1990). A useful but limited consumer's guide. Journal of Career Deuelopment, 17, 129-132.

Jepsen, D.A., Dustin, R., \& Miars, R. (1982). The effects of problem-solving training on adolescents' career exploration and career decision. The Personnel and Guidance

Journal, 61, 149-153.

Johnson, R.G. (1985). Microcomputer-assisted career exploration. The Vocational Guidance Quarterly, 33, 296-304.

Jordaan, J.P. (1963). Exploratory behavior: The formation of self and occupational concepts. In D.E. Super (Eds.), Career Deuelopment:Self-concept theory (pp. 42-78). New

York: College Entrance Examination Board.

Kahneman, D. (1991). Judgment and decision making: A personal view. Psychological Science, 2, 142, 145.

Katz, M. R. (1966). A model of guidance for career decision making. Vocational Guidance Quarterly, 15, 2-10.

Katz, M.R. (1993). Computer-assisted career decision making. Hillsdale, NJ:Erlbaum.

Krumboltz, J. D. (1991). Manual for Career Belief Inuentory. Palo Alto, CA: Consulting Psychologists Press.

Krumboltz, J. D., Scherba, D. S., Hamel, D. A., \& Mitchell, L. K. (1982). Effect of training in rational decision making on the quality of simulated career decisions.

Journal of Counseling Psychology, 29, 618-625.

Leong, F.T.L., \& Morris, J. (1989). Assessing the validity of Holland, Daiger, and Power's measure of Vocational Identity. Measurement and Eualuation in Counseling and Deuelopment, 22, 117-125.

Lichtenberg, J.W., Shaffer, M, \& Arachtingi, B.M. (1993). Expected utility and sequen-tial elimination models of career decision making. Journal of Vocational Behavior, 42, 237-252.

Lucas, E.B., Gysbers, N.C., Buescher, K.L., \& Heppner, P.P. (1988). My Vocational Situation: Normative, psychometric, and comparative data. Measurement and Eualuation in Counseling and Deuelopment, 20, 162-170.

Mann, L. (1989). Becoming a better decision maker.Australian Psychologist, 24, 141155.

Mau, W.C., \& Jepsen, D.A. (1992). Effects of computer-assisted instruction in using formal decision-making strategies to choose a college major. Journal of Counseling Psychology, 39, 185-192.

Mau, W.C. (1997). Assessing the cognitive complexity of vocational value constructs using the career Grid: A comparison of the expressed and supplied methods. Measurement and Eualuation in Counseling and Deuelopment, 29, 202-214.

Miller, M.J., Karriker, C.S., \& Springer, T.P. (1986). A comparison of two approaches to counselor-free career exploration. Journal of Employment Counseling, 23, 339-347. 
PAR (1987). Self-Directed Search: Computer version [computer program]. Odessa, FL: Author.

Pinder F.A., \& Fitzgerald, P.W. (1984). The effectiveness of a computer guidance system in promoting career decision making. Journal of Vocational Behavior, 24, 123-131. Reardon, R.C. (1987). Development of the computer version of the Self-Directed Search. Measurement and Evaluation in Counseling and Development, 20, 62-67.

Reardon, R.C., Lenz, J., Strausberger, S. (1996). Integrating theory, practice and research with SDS: Computer version (Form R). Measurement and Evaluation in Counseling Development, 20, 62-67.

Reardon, R.C., \& Loughead, T. (1988). A comparison of paper-and pencil, and computer version of the Self-Directed Search. Journal of Counseling and Development, 67, 249-252.

Reardon, R.C., Bonnel, R.O., \& Huddleston, M.R. (1982). Self-directed career exploration: A comparison of CHOICES and the Self-Directed Search. Journal of Vocational Behavior, 20, 22-20.

Rubinton, N. (1980). Instruction in career decision making and decision-making styles. Journal of Counseling Psychology, 27, 581-588.

Ryan, C.W., \& Drummond, R.J. (1981). Differential impacts of a computer information system on selected human service agencies. AEDS Journal, 14, 73-83.

Sampson, J.P., Jr. (1983). An integrated approach to computer applications in counseling psychology. The Counseling Psychologist, 11, 65-74.

Sampson, J.P., Jr. (1994). Factors influencing the effective use of computer-assisted career guidance: The North American experience. British Journal of Guidance and Counseling, 22, 91-106.

Sampson, J.P., Jr., Peterson, G.W., \& Reardon, R.C. (1989). Counselor intervention strategies for computer-assisted career guidance: An information-processing approach. Journal of Career Development, 16, 139-154.

Sampson, J.P., Jr., Reardon, R.C., Humphreys, J.K., Peterson, G.W., Evans, M.A., \& Domkowski, D. (1990). A differential feature-cost analysis of nine computer-assisted career guidance system. Journal of Career Development, 17, 81-112.

Tversky, A. (1975). A critique of expected utility theory: Descriptive and normative considerations. Erkenntis, 9, 163-173.

Walsh, W.B., \& Savickas, M.L. (1996). Integrating career theory and practice. In M.L. Savickas, \& W.B. Walsh (Eds.), Handbook of career counseling theory and practice.

Palo Alto, CA: Davies-Black Publishing.

Yongue, I.T., Todd, R.M., \& Burton, J.K. (1981). The effects of didactic classroom instruction versus field exposure on career maturity. Journal of Vocational Behavior, 19, 369-373. 